\title{
A Bifunctional Iminophosphorane Squaramide Catalyzed Enantioselective Synthesis of Hydroquinazolines via Intramolecular Aza-Michael Addition to $\boldsymbol{\alpha}, \boldsymbol{\beta}$-Unsaturated Esters
}

\author{
Guanglong Su, Connor J. Thomson ${ }^{[+]}$, Ken Yamazaki ${ }^{[+]}$, Daniel Rozsar, Kirsten E. Christensen, Trevor \\ A. Hamlin*, and Darren J. Dixon*
}

\begin{abstract}
An efficient synthesis of enantioenriched hydroquinazoline cores via a novel bifunctional iminophosphorane squaramide catalyzed intramolecular aza-Michael addition of urealinked $\alpha, \beta$-unsaturated esters is described. The methodology exhibits a high degree of functional group tolerance around the forming hydroquinazoline aryl core and wide structural variance on the nucleophilic $N$ atom of the urea moiety. Excellent yields (up to 99\%) and high enantioselectivities (up to 97:3 e.r.) using both aromatic and less acidic aliphatic ureas were realized. The potential industrial applicability of the transformation was demonstrated in a $20 \mathrm{mmol}$ scale-up experiment using an adjusted catalyst loading of 2 mol\%. The origin of enantioselectivity and reactivity enhancement provided by the squaramide motif has been uncovered computationally using density functional theory (DFT) calculations, combined activation strain model (ASM) and energy decomposition analysis (EDA).
\end{abstract}

$\mathrm{H}$ eterocyclic organic compounds containing a hydroquinazoline core are commonplace amongst various natural products and potent drug substances used in the clinic. ${ }^{[1]}$ These include, for instance, DPC 963, a second-generation non-nucleoside reverse transcriptase inhibitor (NNRTI) for HIV treatment, ${ }^{[2]}$ fungicidal 2-azolyl-3,4dihydroquinazolines compounds ${ }^{[3]}$ and the anti-human cytomegalovirus drug, letermovir (Figure 1) ${ }^{[4]}$

Although much effort has been directed towards the synthesis of hydroquinazoline compounds, ${ }^{[5]}$ highly enantioselective catalytic methods are still relatively uncommon, especially for unbiased/unactivated systems (Scheme 1). In 2015, the Mashima group developed an enantioselective hydrogenation of quinazolinium salts to yield chiral tetrahydroquinazolines with excellent enantioselectivity under chiral iridium catalysis. ${ }^{[6]} \mathrm{A}$ palladium-catalyzed enantioselective allylic $\mathrm{C}-\mathrm{H}$ amination to generate the chiral hydroquinazoline core in good yield and high enantioselectivity was later described by Gong and coworkers. ${ }^{[7]}$

G. Su, C. J. Thomson ${ }^{[+]}$, K. Yamazaki ${ }^{[+]}$, D. Rozsar, K. E. Christensen, and Prof. D. J. Dixon*

Department of Chemistry, Chemistry Research Laboratory University of Oxford

Mansfield Road, Oxford OX1 3TA (UK)

E-mail: darren.dixon@chem.ox.ac.uk

${ }^{[+]}$These authors contributed equally to this work.

K. Yamazaki, Dr. T. A. Hamlin*

Department of Theoretical Chemistry, Amsterdam Institute of Molecular and Life Sciences (AIMMS), Amsterdam Center for Multiscale Modeling (ACMM), Vrije Universiteit Amsterdam De Boelelaan 1083, 1081 HV Amsterdam, The Netherlands. E-mail: t.a.hamlin@vu.nl

- Supporting information for this article is given via a link at the end of the document.
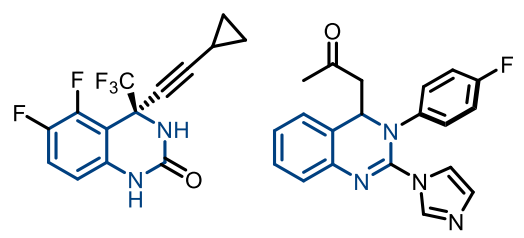

DPC 963 fungicidal activity
on penicillium digitatum

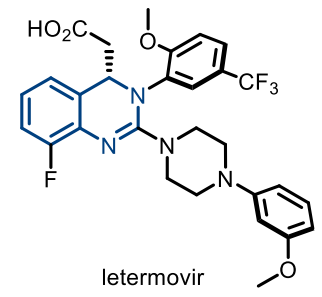

letermovir
Figure 1. Representative pharmaceutically active compounds containing a hydroquinazoline core.

Specifically, for dihydroquinazolines bearing a trifluoromethyl group attached to a newly generated quaternary carbon center, an extensive range of metal and metal-free catalyzed enantioselective addition reactions to reactive cyclic ketimines using alkyne, ${ }^{[8]}$ ketone,${ }^{[9]}$ nitroalkane, ${ }^{[10]} \beta$-keto acid, ${ }^{[11]}$ nitrile, ${ }^{[12]}$ alcohol $^{[13]}$ and isocyanoacetate ${ }^{[14]}$ nucleophiles, have been developed. ${ }^{[15]}$

Enantioselective aza-Michael addition reactions enabled by metal-free catalysts is another powerful and promising approach to access such pharmaceutically relevant $N$-heterocycles. ${ }^{[16]}$ However, in this field, catalyst promoted addition of pronucleophilic ureas to tethered $\beta$-substituted $\alpha, \beta$-unsaturated esters remain largely unsolved due to the high $p K_{\mathrm{a}}$ of the urea and low electrophilicity of the Michael acceptor.[17][18] To our knowledge only two reports describe the synthesis of the chiral hydroquinazoline core in such a way. In 2016, a single moderately enantioselective phase-transfer-catalyzed intramolecular aza-Michael addition (IAMA) was described by Tschaen and coworkers en route to letermovir. ${ }^{[19]}$ In 2017, Ruck and co-workers then developed the enantioselective IAMA reaction of related guanidine containing substrates. ${ }^{[20]}$ However, only $\mathrm{N}$-aryl nucleophiles were compatible and transformation of the guanidine IAMA product to drug molecules bearing urea motifs - such as in DPC 963 (shown in Figure 1) - was not feasible. Against this backdrop, we envisaged that the enhanced Brønsted basicity and broadly tunable structure of the bifunctional iminophosphorane (BIMP) superbase catalyst system developed in our group ${ }^{[21]}$ could provide the solution to the challenging $\mathrm{p} K_{\mathrm{a}}$ related reactivity and modest stereocontrol in the IAMA, and herein we wish to report our findings.

Urea 1a bearing an $\alpha, \beta$-unsaturated tert-butyl ester was chosen as the model substrate for the IAMA reaction. An initial reactivity study of various bifunctional organocatalysts revealed that moderately Brønsted basic cinchona-derived bifunctional catalyst $\mathbf{A}$ failed to promote any detectable reaction in $\mathrm{Et}_{2} \mathrm{O}$ at room temperature after 24 hours (Table 1, entry 1 ). In contrast, catalyst B bearing a superbasic iminophosphorane motif smoothly gave the desired product $\mathbf{2 a}$ in $96 \%$ isolated yield and 
a) enantioselective hydrogenation of quinazolinium salts by Mashima et al. (2015)<smiles>[R]c1cc2ncnc([R])c2cc1[R]</smiles>
$\mathrm{HCl}$

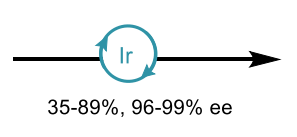<smiles>[R]c1cc2c(cc1[R])[C@@H]([R])NCN2</smiles>

b) enantioselective allylic $\mathrm{C}-\mathrm{H}$ amination by Gong et al. (2017)<smiles>[R]C=C[C@H]1c2ccc([R7])cc2N(Cc2ccc(C)cc2)C(=O)N1[R16]</smiles>

c) enantioselective addition of nucleophiles to reactive cyclic ketimines

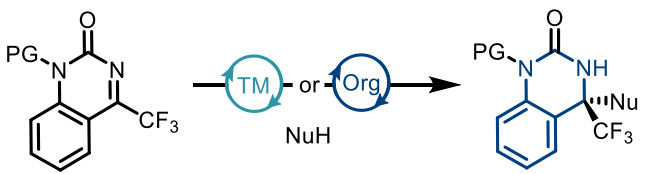

d) intramolecular aza-Michael addition by organocatalysis<smiles>COC(=O)C[C@H]1c2cccc(F)c2NC(=O)N1c1cc(C(F)(F)F)ccc1OC</smiles>

Tschaen et al. (2016)

$100 \%, 56 \%$ ee (single example)<smiles></smiles>

Ruck et al. (2017) $92-100 \%, 68.8-95.2 \%$ ee

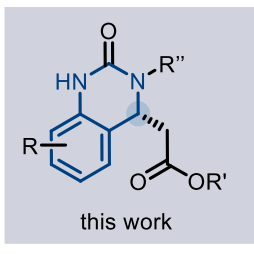

Scheme 1. Previous enantioselective syntheses of hydroquinazoline.

68.5:31.5 er under identical conditions (Table 1, entry 2). With excellent reactivity identified, a series of modifications to the BIMP catalyst structure was then performed to optimise the IAMA reaction. Changing the $\mathrm{H}$-bond donor from a urea to the more acidic thiourea improved the enantioselectivity to $74: 26$ er but lowered the isolated yield to $73 \%$ (Table 1, entry 3 ). The introduction of a second stereogenic center adjacent to the thiourea motif in the catalyst allowed for rapid library generation and solved the issue of poor reactivity (Table 1, entries 4-6). Variation of the chiral backbone and optimization of reaction conditions revealed that $10 \mathrm{~mol} \%$ catalyst $\mathbf{F}$ in $0.025 \mathrm{M}$ toluene at room temperature gave the desired product in almost quantitative yield and 78.5:21.5 er (Table 1, entry 7).

A third stereogenic center adjacent to the amide motif was then incorporated and enantioselectivity increased to 80.5:19.5 er with catalyst $\mathbf{J}$ slightly outcompeting diastereomeric catalyst I (Table 1, entries 10 \& 11). Excitingly, a squaramide substitution for the thiourea (catalyst $\mathbf{K}$ ) boosted the enantiocontrol to 94.5:5.5 er. The major enhancement in selectivity likely arises from the higher acidity / $\mathrm{H}$-bond donor ability of the squaramide and/or the modified 3D structure resulting from the differing bond angles at the squaramide. Additional catalyst structureperformance studies gave no further improvement (see ESI for optimization details).

With the optimal conditions in hand, the scope of the enantioselective IAMA reaction was then explored (Scheme 2A). Notably, the IAMA reactions have typically very clean reaction profiles and no effort was made to exclude moisture or air from the scope experiments. Varying the substituents on the quinazolinone aryl core gave rise to minimal fluctuation in
Table 1. A. Optimization of reaction conditions. B. Selected catalysts investigated.

\begin{tabular}{|c|c|c|c|c|c|}
\hline A & $\mathrm{H}$ & \multicolumn{2}{|c|}{$\frac{\text { catalyst (10 mol\%) }}{\text { solvent, rt, } 24 \mathrm{~h}}$} & \multicolumn{2}{|c|}{$2 a$} \\
\hline Entry & Catalyst & Solvent & Concentration(M) & Yield $(\%)^{[\mathrm{a}]}$ & $e r^{[b]}$ \\
\hline 1 & A & $\mathrm{Et}_{2} \mathrm{O}$ & 0.1 & $<1$ & N.D. \\
\hline 2 & B & $\mathrm{Et}_{2} \mathrm{O}$ & 0.1 & 96 & $68.5: 31.5$ \\
\hline 3 & C & $\mathrm{Et}_{2} \mathrm{O}$ & 0.1 & 73 & $74: 26$ \\
\hline 4 & D & $\mathrm{Et}_{2} \mathrm{O}$ & 0.1 & 99 & $60: 40$ \\
\hline 5 & $E$ & $\mathrm{Et}_{2} \mathrm{O}$ & 0.1 & 96 & $74.5: 25.5$ \\
\hline 6 & $\mathrm{~F}$ & $\mathrm{Et}_{2} \mathrm{O}$ & 0.1 & $>99$ & $75: 25$ \\
\hline 7 & $\mathrm{~F}$ & Toluene & 0.025 & $>99$ & $78.5: 21.5$ \\
\hline $8^{[\mathrm{c}]}$ & G & Toluene & 0.025 & 53 & $67.5: 32.5$ \\
\hline $9^{[c]}$ & $\mathrm{H}$ & Toluene & 0.025 & 11 & $65.5: 34.5$ \\
\hline $10^{[\mathrm{d}]}$ & 1 & Toluene & 0.025 & 76 & $79: 21$ \\
\hline $11^{[\mathrm{d}]}$ & $\mathrm{J}$ & Toluene & 0.025 & 71 & $80.5: 19.5$ \\
\hline 12 & $\mathrm{~K}$ & Toluene & 0.025 & $>99$ & $94.5: 5.5$ \\
\hline
\end{tabular}<smiles>C=C1C2CCN1CC2C(CNC(=O)Nc1cc(C(F)(F)F)cc(C(F)(F)F)c1)c1ccnc2ccc(OC)cc12</smiles><smiles>CC(C)(C)C(CN=[P+]=O)NC(=S)Nc1cc(C(F)(F)F)cc(C(F)(F)F)c1</smiles><smiles>CC(C)(C)C(CN=[P+]=O)NC(=O)Nc1cc(C(F)(F)F)cc(C(F)(F)F)c1</smiles>

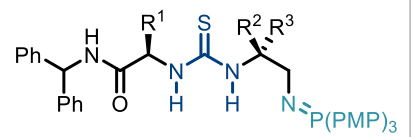

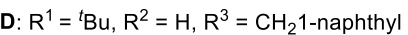
$E: R^{1}={ }^{t} B u, R^{2}=C_{2} 1$-naphthyl, $R^{3}=H$

$F: R^{1}={ }^{t} B u, R^{2}=P h, R^{3}=H$ G: $R^{1}=\operatorname{Pr}, R^{2}=P h, R^{3}=H$ $H: R^{1}=P h_{2} C H, R^{2}=P h, R^{3}=H$

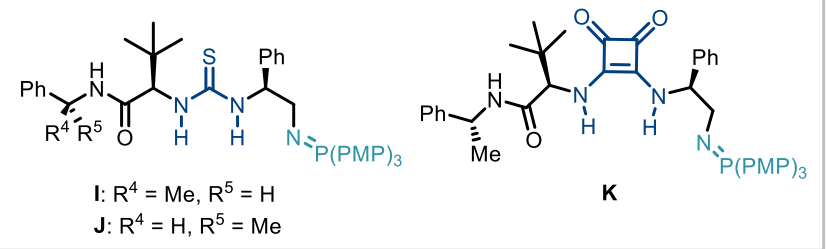

[a] Yields of isolated products. [b] Determined by HPLC analysis on chiral stationary phase. [c] 12 days reaction time. [d] 4 hours reaction time. [e] 10 hours reaction time. N.D. = not determined.

enantioselectivity and compatible functionalities varied from electron-donating groups to electron-withdrawing groups. Elevated temperatures of up to $80^{\circ} \mathrm{C}$ were required to ensure solubility of the substrates in some cases (1b and $\mathbf{1 d}$ ). A pyridine-based substrate (1i) was also found to be well-tolerated affording the desired product in excellent yield and enantioselectivity under the standard reaction conditions. The substituent effect on the $\mathrm{N}$-aryl ring was then examined. Substrates possessing single iodine, bromine and fluorine atoms at various ring positions as well as a 3,5-dichloro example, performed typically well providing the desired hydroquinazoline 


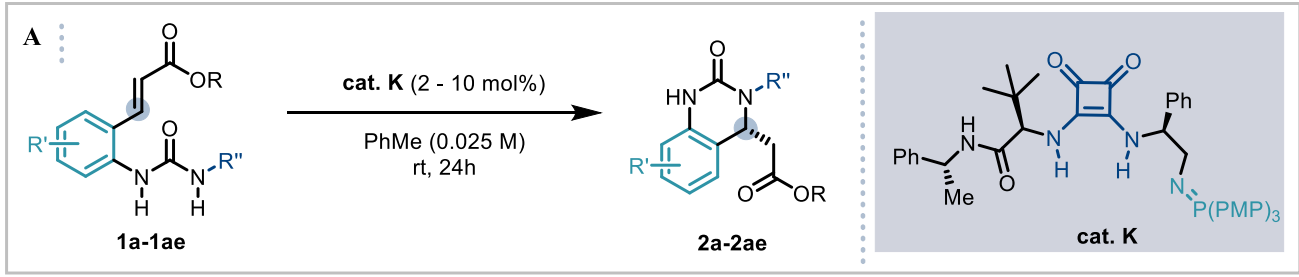<smiles>CCCCOC(=O)C[C@H]1c2ccccc2NC(=O)N1c1ccccc1</smiles>

2a, $99 \%$ 94.5:5.5 er<smiles>CCCCC(=O)C[C@H]1c2cc(C(F)(F)F)ccc2NC(=O)N1c1ccccc1</smiles><smiles>CCC(C)OC(=O)C[C@H]1c2ccccc2NC(=O)N1c1ccc(F)cc1</smiles>

2m, $95 \%$ $92: 8$ er<smiles>CCCCOC(=O)C[C@H]1c2ccccc2NC(=O)N1c1ccc(OC(F)(F)F)cc1</smiles>

2s, $99 \%$ 90:10 er<smiles>CCCC(=O)C[C@H]1c2ccccc2NC(=O)N1c1ccccc1I</smiles>
2y, $91 \%$ [d] $96: 4$ er
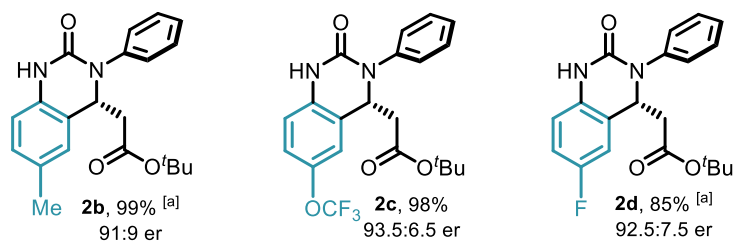
92.5:7.5 er
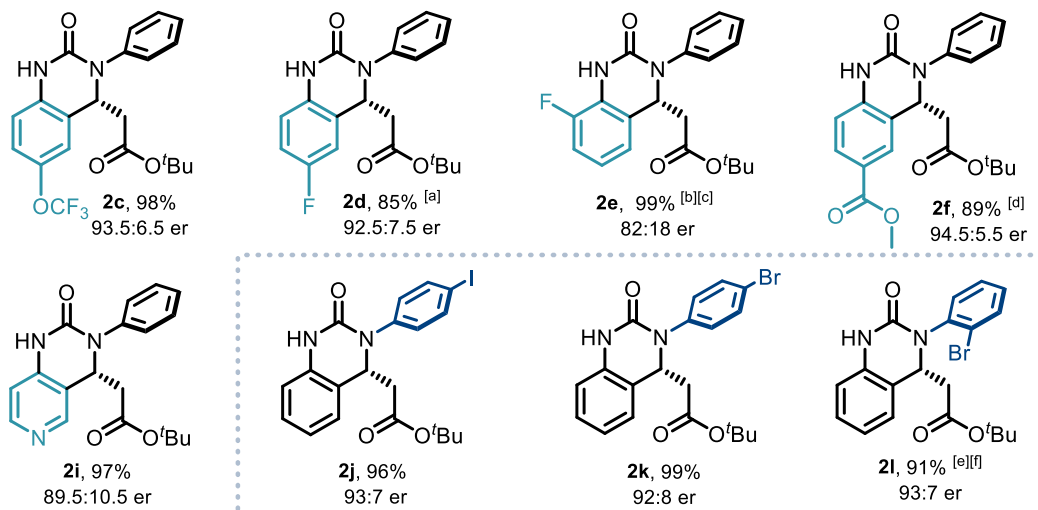

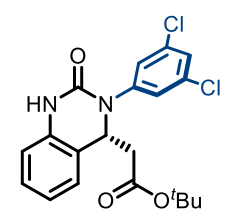

2p, $98 \%$ 87.5:12.5 er

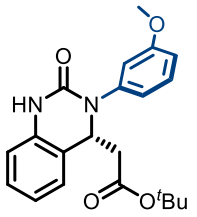

2v, $97 \%{ }^{[\mathrm{g}]}$ 93:7 er

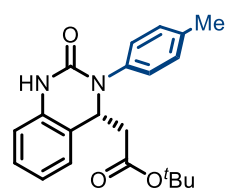

2q, $88 \%$ [d] 94:6 er

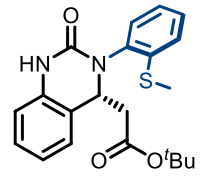

2w, $98 \%$ [g] $96: 4$ er<smiles>CCCCCN1C(=O)Nc2ccccc2[C@H]1CC(=O)OCCC</smiles>

2ac, $72 \%$ [a][e] $86: 14$ er

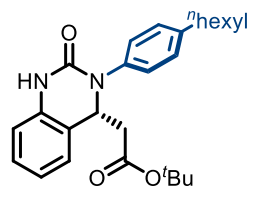

2 r, $91 \%$ [d]

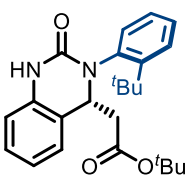

2x, $90 \%{ }^{[g]}$

B : Preparative scale synthesis of $\mathbf{2} \mathbf{j}$<smiles>CCCCOC(=O)/C=C/c1ccccc1NC(=O)Nc1ccc(I)cc1</smiles>

1j

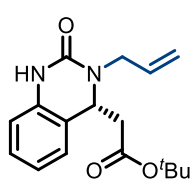

2z, $99 \%, 85: 15$ er $^{[\mathrm{h}]}$ $99 \%, 86.5: 13.5 \mathrm{er}^{[\mathrm{b}][\mathrm{e}]}$

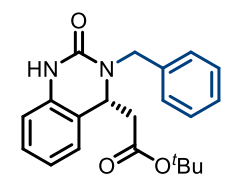

2aa, $96 \%{ }^{[c][g]}$ $85: 15$ er

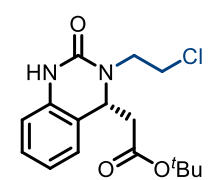

2ab, $96 \%$ [i] $81: 19$ er $72 \% \mathrm{nmr}$ conversion in $48 \mathrm{~h}$

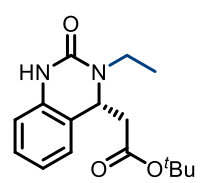

2ad, 57\%, 89:11 er e[] $^{[\mathrm{j}}$ $64 \%, 82.5: 17.5 \mathrm{er}^{[\mathrm{a}][\mathrm{d}]}$ $50{ }^{\circ} \mathrm{C}, 20 \mathrm{~h}$ 5 er after single recrystalization

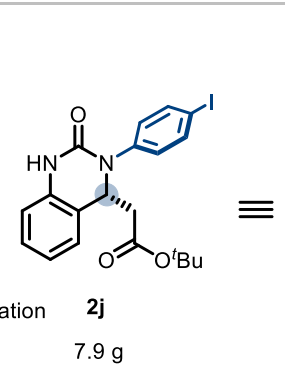

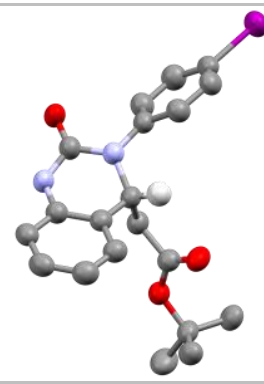

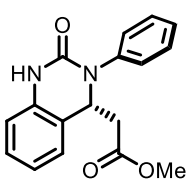

2ae, $99 \%$ [d]

92:8 er

Scheme 2. A. Scope of the BIMP-catalyzed Intramolecular aza-Michael addition to $\alpha, \beta$-unsaturated ester. [a] Reaction carried out at $80{ }^{\circ} \mathrm{C}$. [b] Reaction carried out at $40{ }^{\circ} \mathrm{C}$. [c] 30 hours reaction time. [d] 48 hours reaction time. [e] 72 hours reaction time. [f] 5 mol\% cat. $\mathbf{K}$ was used. [g] Reaction carried out at $50{ }^{\circ} \mathrm{C}$. [h] Reaction carried out at $60^{\circ} \mathrm{C}$. [i] 120 hours reaction time. [j] 216 hours reaction time. B. Preparative scale synthesis of $2 \mathrm{j}$. Stereochemical configuration was assigned by analogy with $(R)-\mathbf{2} \mathbf{j}$ (determined by single crystal X-ray diffraction studies). ${ }^{[22]}$ 
core in excellent yield and good er (1j to $\mathbf{1 p})$. The rates of the cyclization reactions were found to decrease with increasing electron-richness of the $\mathrm{N}$-aryl rings. For substrates $\mathbf{1 q}$ to $\mathbf{1 y}$, extra reaction time or heating to $50{ }^{\circ} \mathrm{C}$ was required to maintain the high yield without compromising enantioselectivity. However, the positional effect of the substituents on reaction enantioselectivity was negligible (1t to $\mathbf{1 v}$ ). Interestingly, ortho substituents (such as thiomethyl, tert-butyl and ethynyl in 1w-1y) gave rise to a slight uplift in enantioselectivity (96:4 - 97:3 er). The methodology was also applicable to less activated, higher $\mathrm{p} K_{\mathrm{a}}$, alkyl-substituted ureas. The high Brønsted basicity of the BIMP catalyst system indeed smoothly provided $\mathrm{N}$-allyl and $\mathrm{N}$ benzyl substituted hydroquinazolines in almost quantitative yield and good er (85:15). Even less activated ureas (1ab to 1ad) demanded harsher reaction conditions to deliver the cyclized product in moderate to excellent yield and good er. Finally, the methyl ester acceptor (1ae) also proved to be a good substrate. After 48 hours hydroquinazoline product 2ae was obtained in almost quantitative yield in high enantioselectivity (92:8 er).

Increasing the reaction scale 100 fold (to $20 \mathrm{mmol}$ ) and decreasing the catalyst loading to $2 \mathrm{~mol} \%$ delivered the desired product in good yield $(7.9 \mathrm{~g}, 85 \%)$ without compromising enantioselectivity (92.5:7.5 er). Pleasingly, only a single recrystallization was required to afford essentially enantiopure $\mathbf{2 j}$ (Scheme 2B). Furthermore, and to demonstrate potential industrial applicability of the chemistry, various derivatizations of this product were carried out. For example, removal of the tertbutyl carboxylate ester with TFA, activation as the acid chloride, and subsequent treatment with benzyl amine and methanol gave the methyl ester (3) and amide (4) in excellent to moderate yield, respectively. Suzuki coupling with an $\mathrm{N}$-methyl substituted pyrazole boronic acid and Sonogashira coupling with erlotinib successfully installed various functionalities in the para-position of the $\mathrm{N}$-aryl ring.

To elucidate the origin of stereocontrol in the novel BIMP squaramide catalysed IAMA reaction, we performed a state-ofthe-art DFT study. Due to the conformational freedom and the existence of two potential activation modes of the BIMP catalyst, we considered a Curtin-Hammett kinetic profile and computed all the possible TSs on the stereoselectivity-determining Michael addition step (see Supporting Information for more details). ${ }^{[23]}$ The most energetically preferred transition structures that lead to either $(R)$ - or $(S)$-product are shown in Scheme 4. The TSModeA-LA1-RA1- $\boldsymbol{R}$ that forms the $(R)$-product was found to be favoured by $1.2 \mathrm{kcal} \mathrm{mol}^{-1}$, which agrees with the experimentally confirmed absolute stereochemical configuration by single crystal $\mathrm{X}$-ray diffraction studies. This preferred TS conformation in TS-ModeA-LA1-RA1- $\boldsymbol{R}$ engages in several stabilising weak interactions, including hydrogen bonding, $\mathrm{CO}-\pi$, and $\mathrm{CH}-\pi$ interactions between the catalyst and the substrate, as well as internal hydrogen bonding between the $\mathrm{PPh}_{3}$ and the squaramide carbonyl oxygen. This conformation creates a custom-fit pocket within which the substrate can perfectly fit without a steric repulsion during the $\mathrm{C}-\mathrm{N}$ bond forming step of the Michael addition. Analysis of non-covalent interaction ( $\mathrm{NCl}$ ) plots allows one to qualitatively visualise these weak interactions between the catalyst and the substrate (Scheme S5 and S6). ${ }^{[24]}$ Therefore, the TS that has a catalyst conformation and coordination mode of the substrate that both reduces steric repulsion and maximises interactions is energetically preferred in this reaction.

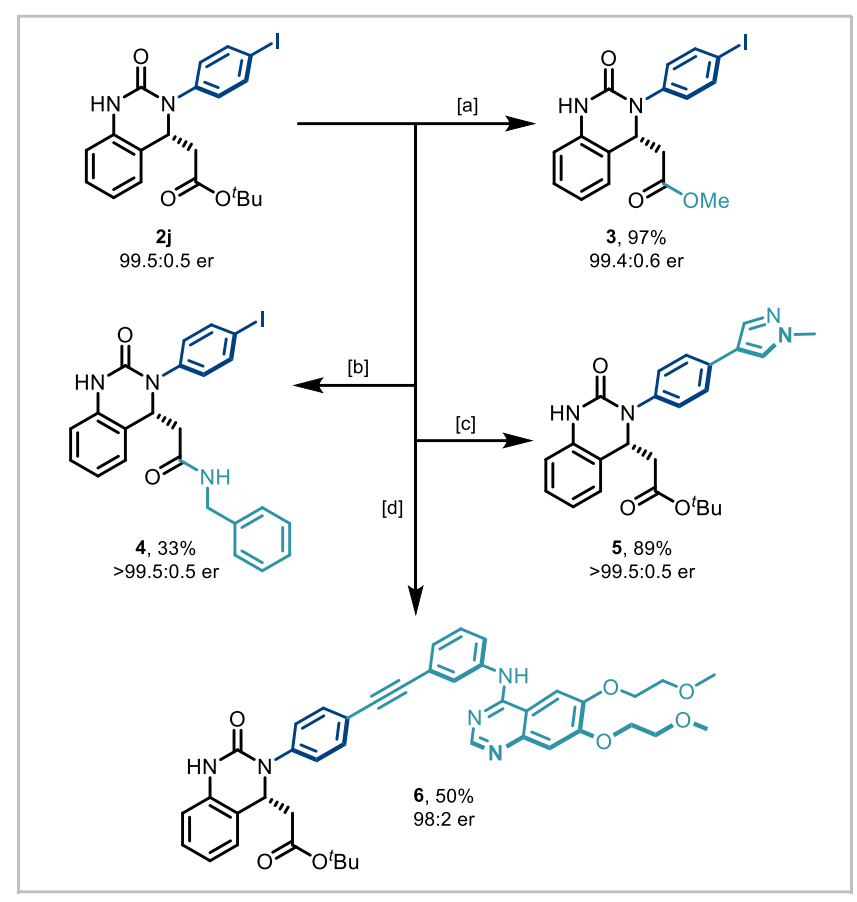

Scheme 3. Derivatization of enantioenriched 2j. [a] i. TFA, $\mathrm{CH}_{2} \mathrm{Cl}_{2}, 0^{\circ} \mathrm{C}$ to $\mathrm{RT}$, 5 h. ii. $\mathrm{SOCl}_{2}, \mathrm{MeOH}, 20$ h. [b] i. TFA, $\mathrm{CH}_{2} \mathrm{Cl}_{2}, 0^{\circ} \mathrm{C}$ to RT, 5 h. ii. $(\mathrm{COCl})_{2}, \mathrm{DMF}$ (cat.), $\mathrm{CH}_{2} \mathrm{Cl}_{2}, 2$ h. iii. $\mathrm{BnNH}_{2}, \mathrm{Et}_{3} \mathrm{~N}, \mathrm{CH}_{2} \mathrm{Cl}_{2}, 18$ h. [c]. 1-Methyl-1H-pyrazole-3boronic acid pinacol ester, $\mathrm{Pd}(\mathrm{dppf}) \mathrm{Cl}_{2} \mathrm{CH}_{2} \mathrm{Cl}_{2}, \mathrm{Cs}_{2} \mathrm{CO}_{3}$, 1,4-dioxane, $\mathrm{H}_{2} \mathrm{O}$. [d] erlotinib ( $\mathrm{HCl}$ complex), $\mathrm{PdCl}_{2}\left(\mathrm{PPh}_{3}\right)_{2}, \mathrm{Cul}, \mathrm{PPh}_{3}, \mathrm{Et}_{3} \mathrm{~N}$.

In order to obtain deeper insight into the origin of the catalytic activity imparted by the squaramide motif of the BIMP catalyst, an activation strain analysis (ASA) and an energy decomposition analysis (EDA) were carried out on perfect archetypal model systems. The ASM involves decomposing the electronic energy $\Delta E$ into the strain energy $\Delta E_{\text {strain }}$ associated with the structural deformation of the hydrogen bond donor (HB) and methyl acrylate (MA) from their equilibrium geometry and the interaction energy $\Delta E_{\text {int }}$ between the deformed reactants. ${ }^{[25]}$ The EDA separates the interaction energy ( $\left.\Delta E_{\text {int }}\right)$ into the following three chemically meaningful energy terms: classical electrostatic interaction $\left(\Delta V_{\text {elstat }}\right)$, Pauli repulsion $\left(\Delta E_{\text {pauli }}\right)$ between closedshell orbitals which is responsible for steric repulsion, and stabilising orbital interaction $\left(\Delta E_{\mathrm{oi}}\right)$ that accounts, among others, for HOMO-LUMO interactions. ${ }^{[26]}$ First, we analyzed the interaction between HB and MA (Scheme 5A). The interaction becomes more stabilising from urea to thiourea to squaramide $\left(\Delta E_{\text {int }}=-9.0\right.$ to -10.1 to $\left.-11.5 \mathrm{kcal} \mathrm{mol}^{-1}\right)$ mainly due to the more stabilizing $\Delta V_{\text {elstat }}$ term by the electrostatic nature of the hydrogen bonding interaction. The $\Delta E_{\mathrm{oi}}$ term is also important and involves significant charge transfer from the lone pair of the oxygen atom of MA and the two $\sigma^{*} \mathrm{~N}-\mathrm{H}$ orbitals on the $\mathrm{HB}$, which leads to polarization of the $\pi-\mathrm{MO}$ away from the $\mathrm{C}=\mathrm{C}$ bond (the importance of which is explained below). We then analysed the transition structures and the energy barriers for the aza-Michael addition (Scheme $5 \mathrm{~B}$ ). The uncatalyzed reaction goes with the highest reaction barrier $\left(\Delta G^{+}=16.3 \mathrm{kcal} \mathrm{mol}^{-1}\right)$. The urea, thiourea, and squaramide catalyzed reactions go with barriers of $12.0,11.2$, and $8.9 \mathrm{kcal} \mathrm{mol}^{-1}$, respectively.

The enhanced reactivity of the catalysed reactions originates from a reduction of Pauli repulsion between the reactants. ${ }^{[27]}$ The 


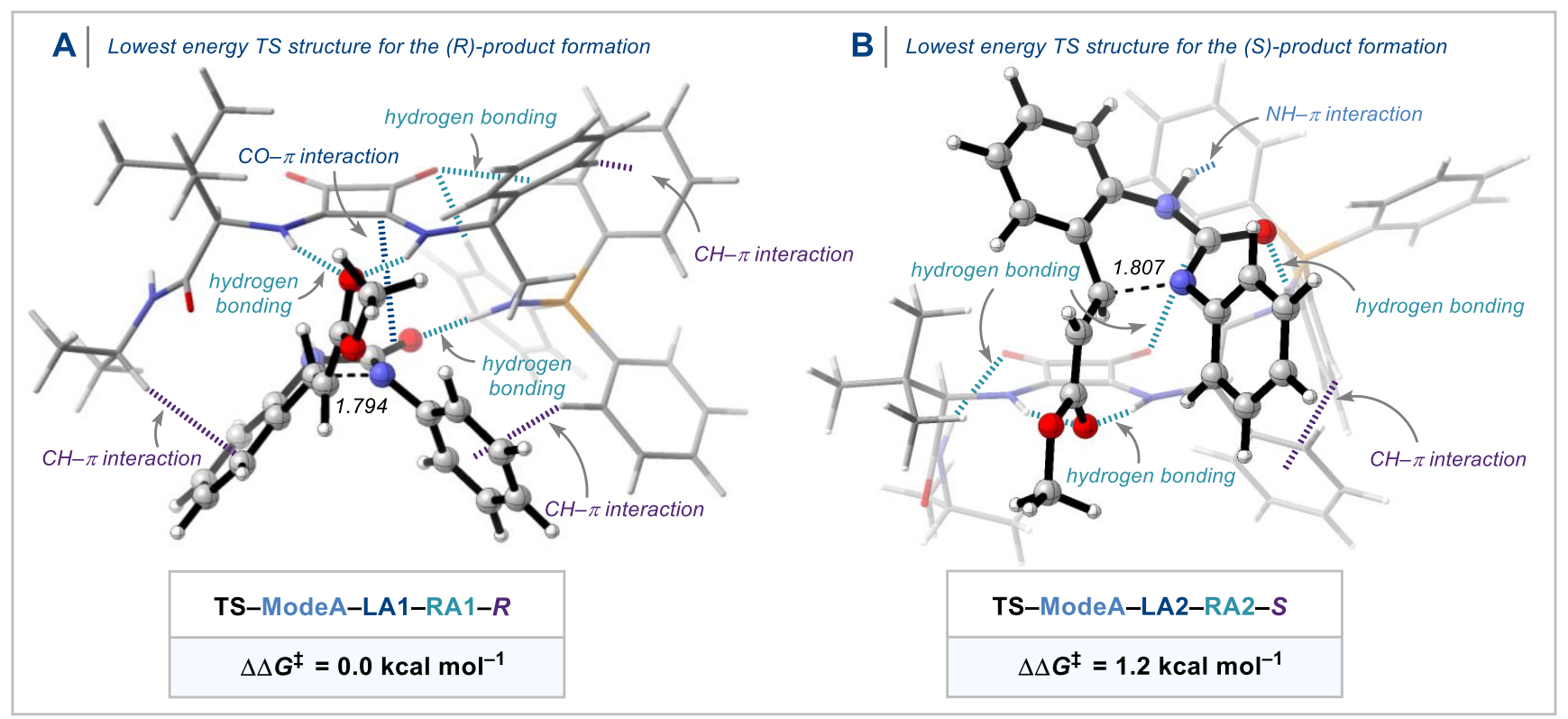

Scheme 4. A. Lowest energy TS structure for the formation of $(R)$-product and B. lowest energy TS structure for the formation of $(S)$-product of the BIMP squaramide-catalyzed intramolecular aza-Michael addition computed at COSMO(toluene)-ZORA-M06-2X/TZ2P//COSMO(toluene)-ZORA-BLYP-D3(BJ)/DZP. Energies $\left(\mathrm{kcal} \mathrm{mol}^{-1}\right)$ and forming bond lengths $(\AA)$ of TS geometries are provided in the insert.

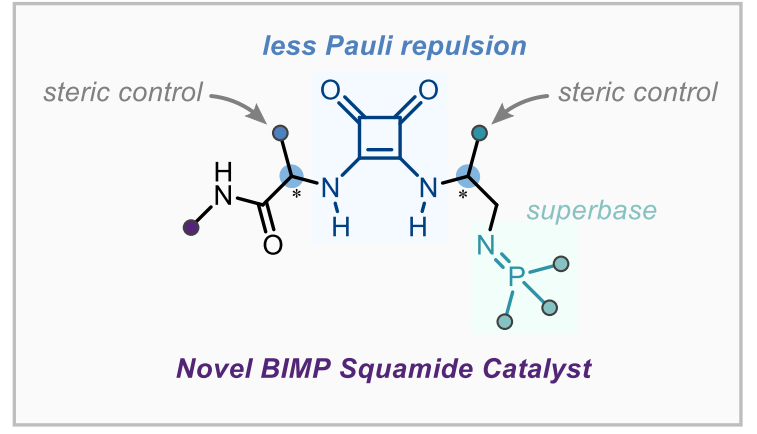

B | Transition structures of $\mathrm{H}$-bond donor-catalyzed aza-Michael addition

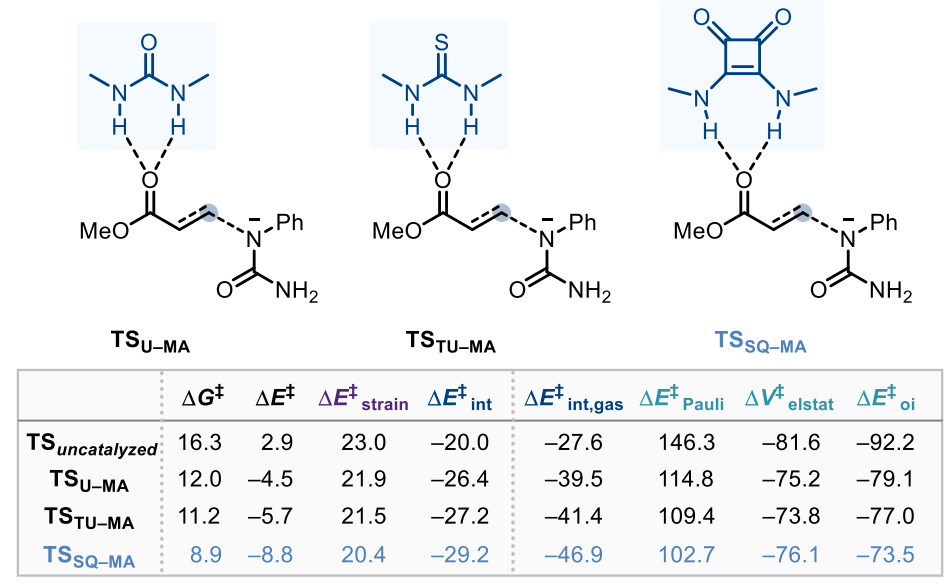

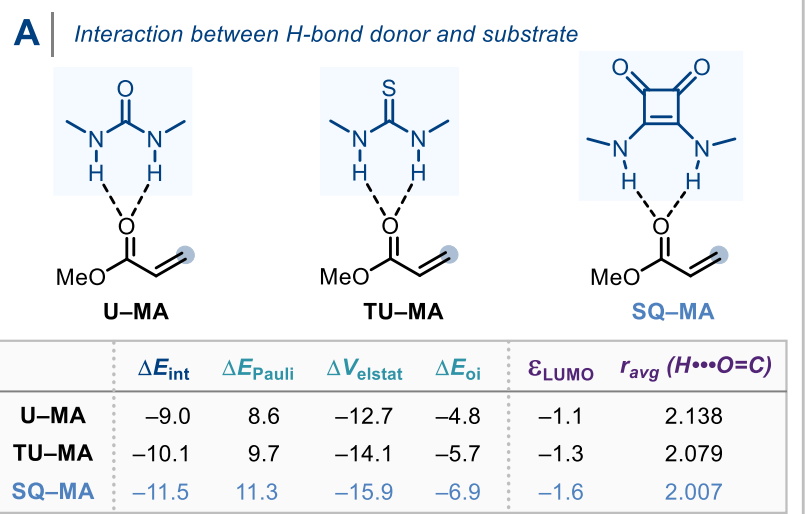

C $\mid$ Origin of reduced Pauli repulsion with squaramide catalyst

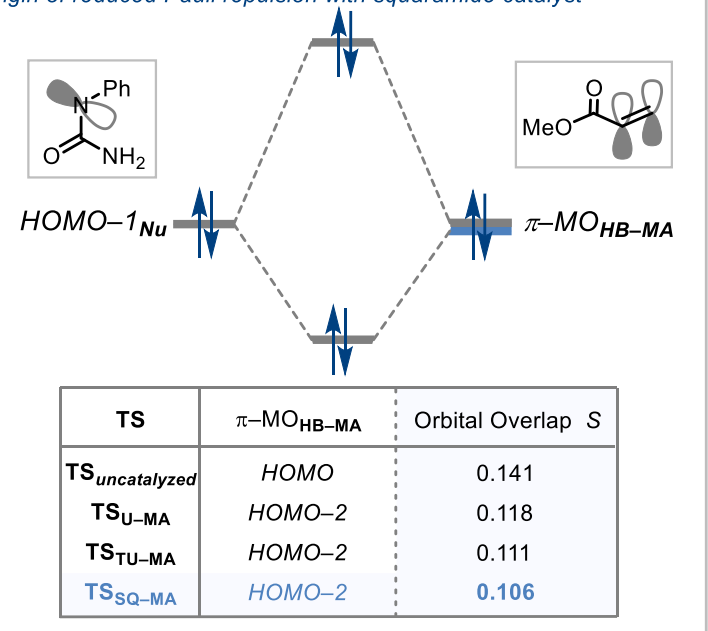

Scheme 5. A. Interaction energies and the energy decomposition analysis (EDA) of the hydrogen bond donor-methyl acrylate complexes (HB-MA). B. Energy barriers of the aza-Michael addition transition structures and the activation strain analysis (ASA) and the energy decomposition analysis (EDA). C. Molecular orbital diagram and the most significant occupied orbital overlaps computed at COSMO(toluene)-ZORA-M06-2X/TZ2P//COSMO(toluene)-ZORA-BLYPD3(BJ)/DZP. Energies (kcal mol ${ }^{-1}$ ) are provided in the insert. 
origin of the less destabilising Pauli repulsion $\left(\Delta E^{\ddagger_{\text {Pauli }}}\right)$ for the transformation was quantified by performing a Kohn-Sham molecular orbital (KS-MO) analysis (Scheme $5 \mathrm{C}$ ). The occupied $\pi$-MOHB-MA $\left(2_{p \pi}\right.$ atomic orbitals on the reacting $\mathrm{C}=\mathrm{C}$ double bonds) contributes to the trend in the Pauli repulsion. The computed orbital overlap $S$ between the $\pi$-МОнв-мA and the lone pair of the nucleophile HOMO-1 ${ }_{\mathrm{Nu}}$ decreases from 0.141 for

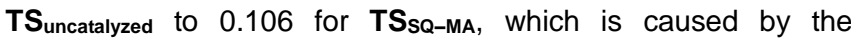
aforementioned polarization of the $\pi$-МОнв-мА away from the reactive carbon centre of the $\mathrm{C}=\mathrm{C}$ bond due to the charge transfer interaction with the hydrogen bond donor catalyst. The squaramide catalyst emerges as the best of our studied bifunctional iminophosphorane squaramide catalysts as it is able to reduce the destabilising Pauli repulsion between the reactants and thereby impart the greatest reactivity enhancement of our novel intramolecular aza-Michael addition. ${ }^{[27]}$

In summary, an efficient and highly enantioselective BIMPcatalysed intramolecular aza-Michael addition affording decorated hydroquinazoline structures with excellent yields and enantiomeric ratios has been developed. A novel BIMP squaramide system was found to be effective in activating both aromatic and aliphatic ureas. DFT calculations uncovered the fact that the optimal catalyst conformation creates a pocket-like binding site for the substrate to impart enantiofacial selectivity, whilst the squaramide motif demonstrates advantages over urea and thiourea $\mathrm{H}$-bond donor groups on decreasing the destabilizing Pauli repulsion between the reactants (combined ASM and EDA). The catalytic ring formation strategy demonstrated broad functional group tolerance including of esters, nitriles, heterocycles, alkenes, and alkynes, and catalyst loading can be lowered down to $2 \mathrm{~mol} \%$ in a multi-gram scale synthesis. The hydroquinazoline aza-Michael addition products were stable towards a series of late-stage structural derivatizations thus demonstrating relevance to pharmaceutical development.

\section{Acknowledgements}

C.J.T. thanks Bayer AG for generous financial support. K.Y. thanks the Honjo International Scholarship Foundation for funding. D.R. thanks the EPSRC Centre for Doctoral Training in Synthesis for Biology and Medicine (EP/L015838/1) for studentships, generously supported by AstraZeneca, Diamond Light Source, Defence Science and Technology Laboratory, Evotec, GlaxoSmithKline, Janssen, Novartis, Pfizer, Syngenta, Takeda, UCB and Vertex. T.A.H. thanks The Netherlands Organization for Scientific Research (NWO) for financial support. This work was carried out on the Dutch national e-infrastructure with the support of SURF Cooperative.

Keywords: enantioselective - aza-Michael • BIMP catalysis • chiral hydroquinazolines $\cdot$ urea activation

[1] a) Shagufta, I. Ahmad, Med. Chem. Commun. 2017, 8, 871-885; b) B. K. Tiwary, K. Pradhan, A. K. Nanda, R. Chakraborty, J. Chem. Biol. Ther. 2015, 1, 104; c) S. Patterson, M. S. Alphey, D. C. Jones, E. J. Shanks, I. P. Street, J. A. Frearson, P. G. Wyatt, I. H. Gilbert, A. H. Fairlamb, J. Med. Chem. 2011, 54, 6514-6530; d) K. Hemalatha, G. Madhumitha, Eur. J. Med. Chem. 2016, 123, 596-630; e) P. Thanigaimalai, K.-C. Lee, S.-C. Bang, J.-H. Lee, C.-Y. Yun, E. Roh, B.-
Y. Hwang, Y. Kim, S.-H. Jung, Bioorg. Med. Chem. 2010, 18, 15551562; f) P. Thanigaimalai, V. K. Sharma, K.-C. Lee, C.-Y. Yun, Y. Kim, S.-H. Jung, Bioorg. Med. Chem. Lett. 2010, 20, 4771-4773; g) H. Hasegawa, M. Muraoka, K. Matsui, A. Kojima, Bioorg. Med. Chem. Lett. 2003, 13, 3471-3475; h) P. Bernardelli, E. Lorthiois, F. Vergne, C. Oliveira, A.-K. Mafroud, E. Proust, N. Pham, P. Ducrot, F. Moreau, M. Idrissi, A. Tertre, B. Bertin, M. Coupe, E. Chevalier, A. Descours, F. Berlioz-Seux, P. Berna, M. Li, Bioorg. Med. Chem. Lett. 2004, 14, 4627-4631; i) N. M. A. Gawad, H. H. Georgey, R. M. Youssef, N. A. ElSayed, Eur. J. Med. Chem. 2010, 45, 6058-6067; j) J. S. Byun, J. M. Sohn, D. G. Leem, B. Park, J. H. Nam, D. H. Shin, J. S. Shin, H. J. Kim, K.-T. Lee, J. Y. Lee, Bioorg. Med. Chem. Lett. 2016, 26, 1073-1079; k) S. Patterson, M. S. Alphey, D. C. Jones, E. J. Shanks, I.P. Street, J.A. Frearson, P.G. Wyatt, I.H. Gilbert, A.H. Fairlamb, J. Med. Chem. 2011, 54, 6514-6530; I) K.-A. S. Schlegel, Z.-Q. Yang, T. S. Reger, Y. Shu, R. Cube, K. E. Rittle, P. Bondiskey, M. G. Bock, G. D. Hartman, C. Tang, J. Ballard, Y. Kuo, T. Prueksaritanont, C. E. Nuss, S. M. Doran, S. V. Fox, S. L. Garson, R. L. Kraus, Y. Li, V. N. Uebele, J. J. Renger, J. C Barrow, Bioorg. Med. Chem. Lett. 2010, 20, 5147-5152;

[2] a) R. W. King, R. M. Klabe, C. D. Reid, S. K. Erickson-Viitanen, Antimicrob. Agents Chemother. 2002, 46, 1640-1646; b) J. W. Corbett, S. S. Ko, J. D. Rodgers, S. Jeffrey, L. T. Bacheler, R. M. Klabe, S. Diamond, C.-M. Lai, S. R. Rabel, J. A. Saye, S. P. Adams, G. L. Trainor, P. S. Anderson, S. K. Erickson-Viitanen, Antimicrob. Agents Chemother. 1999, 43 , 2893-2897; c) J. W. Corbett, S. S. Ko, J. D. Rodgers, L. A. Gearhart, N. A. Magnus, L. T. Bacheler, S. Diamond, S. Jeffrey, R. M. Klabe, B. C. Cordova, S. Garber, K. Logue, G. L. Trainor, P. S. Anderson, S. K. Erickson-Viitanen, J. Med. Chem. 2000, 43, 20192030.

[3] W. J. Li, Q. Li, D. L. Liu, M. W. Ding, J. Agric. Food Chem. 2013, 61, 1419-1426.

[4] a) P. S. Verghese, M. R. Schleiss, Drugs Future. 2013, 38, 291-298; b) T. Goldner, G. Hewlett, N. Ettischer, H. Ruebsamen- Schaeff, H. Zimmermann, P. Lischka, J. Virol. 2011, 85, 10884-10893.

[5] a) V. K. Pandey, M. A. Kumar, N. Trivedi, Indian J. Chem. Sec. B. 2008, 47B, 1910-1914; b) W. Seitz, H. Geneste, G. Backfisch, J Delzer, C. Graef, W. Hornberger, A. Kling, T. Subkowski, N. Zimmermann, Bioorg. Med. Chem. Lett. 2008, 18, 527-531; c) H. Rhim, Y. S. Lee, S. J. Park, B. Y. Chung, J. Y. Lee, Bioorg. Med. Chem. Lett. 2005, 15, 283-286; d) T. Xie, Y. Xiao, S. Zhao, X.-Q. Hu, P.-F. Xu, J. Org. Chem. 2016, 81, 10499-10505; e) J. Willwacher, S. Rakshit, F. Glorius, Org. Biomol. Chem. 2011, 9, 4736-4740; f) Z. Xin, Z. Pei, T. V. Geldem, M. Jirousek, Tetrahedron Lett. 2000, 41, 1147-1150; g) Y. S. Lee, B. H. Lee, S. J. Park, S. B. Kang, H. Rhim, J.-Y. Park, J.-H. Lee S.-W. Jeong, J. Y. Lee, Bioorg. Med. Chem. Lett. 2004, 14, 3379-3384; h) A. V. Ivachtchenko, S. M. Kovalenko, O. G. Drushlyak, J. Comb. Chem. 2003, 5, 775-788; i) S. Fukamachi, H. Konishi, K. Kobayashi, Synthesis, 2010, 1593-1598; j) K. Kobayashi, Y. Yokoi, H. Konishi, Synthesis, 2011, 1526-1528; k) B. Kaur, R. Kaur, ARKIVOC. 2007, 15, 315-323.

[6] Y. Kita, K. Higashida, K. Yamaji, A. limuro, K. Mashima, Chem. Commun. 2015, 51, 4380-4382.

[7] P. Wang, M. Shen, T. Wang, H. Lin, L. Gong, Angew. Chem. Int. Ed. 2017, 56, 16032-16036; Angew. Chem. 2017, 129,16248-16252.

[8] a) N. A. Magnus, P. N. Confalone, L. Storace, Tetrahedron Lett. 2000 41, 3015-3019; b) G. S. Kauffman, G. D. Harris, R. L. Dorow, B. R. P Stone, R. L. Parsons, J. A. Pesti, N. A. Magnus, J. M. Fortunak, P. N. Confalone, W. A. Nugent, Org. Lett. 2000, 2, 3119-3121; c) B. Jiang, Y. G. Si, Angew. Chem., Int. Ed. 2004, 43, 216-218; d) F.-G. Zhang, H. Ma, J. Nie, Y. Zheng, Q. Gao, J. A. Ma, Adv. Synth. Catal. 2012, 354, 1422-1428

[9] B. Jiang, J. J. Dong, Y. G. Si, X. L. Zhao, Z. G. Huang, M. Xu, Adv. Synth. Catal. 2008, 350, 1360-1366.

[10] H. Xie, Y. Zhang, S. Zhang, X. Chen, W. Wang, Angew. Chem., Int. Ed. 2011, 50, 11773-11776.

[11] a) H. N. Yuan, S. Wang, J. Nie, W. Meng, Q. Yao, J. A. Ma, Angew. Chem., Int. Ed. 2013, 52, 3869-3873; b) H. N. Yuan, S. Li, J. Nie, Y. Zheng, J. A. Ma, Chem. Eur. J. 2013, 19, 15856-15860.

[12] F. G. Zhang, X. Y. Zhu, S. Li, J. Nie, J. A. Ma, Chem. Commun. 2012, $48,11552-11554$ 
[13] D. Zhou, X. Yu, J. Zhang, W. Wang, H. Xie, Org. Biomol. Chem. 2016, 14,6193-6196.

[14] M. X. Zhao, H. L. Bi, R. H. Jiang, X. W. Xu, M. Shi, Org. Lett. 2014, 16, 4566-4569.

[15] S. Li, J. Ma, Chem. Soc. Rev. 2015, 44, 7439-7448.

[16] M. G. Vinogradov, O. V. Turova, S. G. Zlotin, Org. Biomol. Chem. 2019, 17, 3670-3708 and references cited therein.

[17] D. S. Allgäuer, H. Jangra, H. Asahara, Z. Li, Q. Chen, H. Zipse, A. R. Ofial, H. Mayr, J. Am. Chem. Soc. 2017, 139, 13318-13329.

[18] For intermolecular examples, see: a) G. Sundararajan, N. Prabagaran, Org. Lett. 2001, 3, 389-392; b) Y. Lin, W. J. Hirschi, A. Kunadia, A. Paul, I. Ghiviriga, K. A. Abboud, R. W. Karugu, M. J. Vetticatt, J. S. Hirschi, D. Seidel, J. Am. Chem. Soc. 2020, 142, 5627-5635.

[19] G. R. Humphrey, S. M. Dalby, T. Andreani, B. Xiang, M. R. Luzung, Z. J. Song, M. Shevlin, M. Christensen, K. M. Belyk, D. M. Tschaen, Org. Process Res. Dev. 2016, 20, 1097-1103.

[20] C. K. Chung, Z. Liu, K. W. Lexa, T. Andreani, Y. Xu, Y. Ji, D. A. DiRocco, G. R. Humphrey, R. T. Ruck, J. Am. Chem. Soc. 2017, 139, 10637-10640.

[21] M. Formica, D. Rozsar, G. Su, A. J. M. Farley and D. J. Dixon, Acc. Chem. Res., 2020, 53, 2235-2247 and references cited therein.

[22] Low temperature single crystal $\mathbf{X}$-ray diffraction data for $\mathbf{2 j}$ was collected using a Rigaku Oxford SuperNova diffractometer. Raw frame data were reduced using CrysAlisPro and the structures were solved using 'Superflip' [L. Palatinus and G. Chapuis, J. Appl. Cryst., 2007, 40, 786-790.] before refinement with CRYSTALS [a) P. Parois, R.I. Cooper and A.L. Thompson Chem. Cent. J., 2015, 9:30. b) R. I. Cooper, A. L. Thompson and D. J. Watkin, J. Appl. Cryst. 2010, 43, 1100-1107.] as per the SI (CIF). Full refinement details are given in the Supporting Information (CIF); Crystallographic data have been deposited with the Cambridge Crystallographic Data Centre (CCDC 2054508) and can be obtained via www. ccdc.cam.ac.uk/data_request/cif.

[23] a) J. C. Golec, E. M. Carter, J. W. Ward, W. G. Whittingham, L. Simon, R. S. Paton, D. J. Dixon, Angew. Chem. Int. Ed., 2020, 59, 1741717422; b) M. Formica, G. Sorin, A. J. M. Farley, J. Díaz, R. S. Paton, D. J. Dixon, Chem. Sci. 2018, 9, 6969-6974; c) H. Shi, I. N. Michaelides, B. Darses, P. Jakubec, Q. N. N. Ngu-yen, R. S. Paton, D. J. Dixon, J. Am. Chem. Soc. 2017, 139, 17755-17758.

[24] a) E. R. Johnson, S. Keinan, P. Mori-Sánchez, J. Contreras-García, A. J. Cohen, W. Yang, J. Am. Chem. Soc. 2010, 132, 6498-6506; b) J. Contreras-García, E. R. Johnson, S. Keinan, R. Chaudret, J.-P. Piquemal, D. N. Beratan, W. Yang, J. Chem. Theory Comput. 2011, 7, 625-632.

[25] a) P. Vermeeren, S. C. C. van der Lubbe, C. Fonseca Guerra, F. M. Bickelhaupt, T. A. Hamlin, Nature Protoc, 2020, 15, 649-667; b) F. M. Bickelhaupt, K. N. Houk, Angew. Chem. Int. Ed. 2017, 56, 1007010086; c) L. P. Wolters, F. M. Bickelhaupt, WIRES Comput. Mol. Sci. 2015, 5, 324-343; d) I. Fernández, F. M. Bickelhaupt, Chem. Soc. Rev. 2014, 43, 4953-4967; e) W.-J. van Zeist, F. M. Bickelhaupt, Org Biomol. Chem. 2010, 8, 3118-3127.

[26] F. M. Bickelhaupt, E. J. Baerends, in Reviews in Computational Chemistry (Eds.: K. B. Lipkowitz, D. B. Boyd), Wiley, Hoboken, 2000, pp. $1-86$.

[27] a) T. A. Hamlin, I. Fernandez, F. M. Bickelhaupt, Angew. Chem. Int. Ed. 2019, 58, 8922-8926; b) P. Vermeeren, T. A. Hamlin, I. Fernandez, F. M. Bickelhaupt, Angew. Chem. Int. Ed. 2020, 59, 6201-6206; c) P. Vermeeren, F. Brinkhuis, T. A. Hamlin, F. M. Bickelhaupt, Chem. Asian J. 2020, 15, 1167-1174; d) P. Vermeeren, T. A. Hamlin, I. Fernandez, F. M. Bickelhaupt, Chem. Eur J. DOI: 10.1002/chem.202004496. 